JebB, W. H. H. \& Tomlinson, A. H. (1957). J. gen. Microbiol. 17, 59-63

\title{
The Minimal Amino Acid Requirements of Haemophilus pertussis
}

\author{
By W. H. H. JEBB AND A. H. TOMLINSON \\ Public Health Laboratory, Walton Street, Oxford
}

\begin{abstract}
SUMMARY: Of 13 sulphur-containing compounds tested only cystine, cysteine and glutathione satisfied the sulphur requirements of the strains of Haemophilus pertussis used when grown in a defined liquid medium containing 15 amino acids. Very small inocula (3-10 viable organisms) of 8 strains grew in a medium containing glutamic acid + cystine as the only amino acids added. Four strains were carried through 9 subcultures in this medium.
\end{abstract}

Previous work on the sulphur requirements of Haemophilus (Bordetella) pertussis has produced conflicting results. Different workers(Hornibrook, 1939; Verwey, Thiele, Sage \& Schuchardt, 1949; Ungar, James, Muggleton, Pegler \& Tomich, 1950; Proom, 1955) found that cystine, cysteine or glutathione supplied a requirement needed for full growth of large inocula. Imamura (1952), however, obtained growth with a wider variety of sulphur sources, including some inorganic compounds. The observations of Jebb \& Tomlinson (1955), who used small inocula, suggested that cystine itself was not an essential requirement for growth. There are also conflicting results regarding the other amino acid requirements of $\boldsymbol{H}$. pertussis. Imamura (1952) and Jebb \& Tomlinson (1955) showed that $\boldsymbol{H}$. pertussis would grow in media containing cystine + glutamic acid as the only amino acids. On the other hand, Proom (1955) stated that at least eight amino acids must be present in a medium if it were to support the growth of $\boldsymbol{H}$. pertussis in serial subculture. A re-investigation of the sulphur and minimal amino acid requirements of $H$. pertussis has now been made.

\section{METHODS}

Strains. Some of the strains of Haemophilus pertussis used were isolated in this laboratory, and others were kindly supplied by Dr Elizabeth Rowatt (Lister Institute, Elstree). All strains used were freeze-dried from the first or second subculture after isolation; strain 724 was used in previous work (Jebb \& Tomlinson, 1951, 1955).

Preparation of inocula. One- or two-day cultures on Bordet-Gengou medium were inoculated heavily on to this medium and incubated at $35^{\circ}$ for $18 \mathrm{hr}$. The organisms were then washed off with saline, centrifuged, washed twice with saline, resuspended to known opacity and diluted for use. The standard inoculum was $0.1 \mathrm{ml}$. diluted suspension and was shown by colony counts to contain about $1 \times 10^{3}$ viable organisms.

Conditions of incubation and measurement of growth. Five ml. of medium were placed in 6 in. $\times \frac{5}{8}$ in. test tubes, which had been bent at an angle of $45^{\circ}$, $1 \frac{1}{2}$ in. from the open end. The tubes were incubated with the longer part 
horizontal, at $35^{\circ}$. The amount of growth was recorded as the mean optical density (extinction) of triplicate tubes, as described by Jebb \& Tomlinson (1955).

Basal medium for the investigation of sulphur requirements. This medium was made up to four-fifths final volume so that $1.0 \mathrm{ml}$. volumes of the various supplements might be added aseptically to $4.0 \mathrm{ml}$. basal medium to give a final volume of $5 \mathrm{ml}$. The basal medium, when diluted to final volume, contained, (i) (amounts/l.): $\mathrm{KH}_{2} \mathrm{PO}_{4}, 0.5$ g.; $\mathrm{NaCl}, 6.2$ g.; $\mathrm{MgCl}_{2}, 0.04$ g.; $\mathrm{FeCl}_{3}$, $0.01 \mathrm{~g}$; soluble starch, $1.5 \mathrm{~g}$; (ii) amino acids $\left(\times 10^{-4} \mathrm{M}\right): 2.7 \mathrm{~L}$-alanine, 8.0 L-arginine, $6.0 \mathrm{~L}$-aspartic acid, $100.0 \mathrm{~L}$-glutamic acid, 3.0 glycine, $1.7 \mathrm{~L}$-histidine, $4 \cdot 0 \mathrm{~L}$-isoleucine, $6.0 \mathrm{~L}$-leucine, $5 \cdot 0 \mathrm{~L}$-lysine, $0.5 \mathrm{~L}$-phenylalanine, $7 \cdot 3 \mathrm{~L}$-proline, 2.0 DL-serine, $2.0 \mathrm{DL}$-threonine, $4.0 \mathrm{~L}$-tyrosine and $1.5 \mathrm{~L}$-valine; (iii) $10^{-5} \mathrm{M}$ nicotinic acid; (iv) the following growth factors $(\mu \mathrm{g} . / \mathrm{ml}):$.6.0 guanine, 6.0 hypoxanthine, 6.0 xanthine, 1.0 haemin and 0.05 biotin. This basal medium was tubed in $4.0 \mathrm{ml}$. volumes and autoclaved at $10 \mathrm{lb} . / \mathrm{sq} . \mathrm{in}$. $\left(115^{\circ}\right)$ for $20 \mathrm{~min}$.

Medium $G$ contained salts and starch at the concentrations given above and $0.01 \mathrm{M} \mathrm{L}$-glutamic acid $+10^{-4} \mathrm{M} \mathrm{L}$-cystine as the only amino acids added.

Medium $G F$ consisted of medium $\mathbf{G}+$ the growth factors listed above.

The various growth factors and amino acids were obtained from British Drug Houses Ltd. and Roche Products Ltd. The glutamic acid was purified by recrystallization from water six times (see below).

\section{RESULTS}

\section{Sulphur requirements}

Because most of the amino acids used by Jebb \& Tomlinson (1955) were natural L-isomers it was possible that cystine or cysteine was present as an impurity in one of them, and glutamic acid, being present in the highest concentration $(0.01 \mathrm{M})$, was most suspect. When tested by the cyanide-nitroprusside reaction, the sample of L-glutamic acid which had been used was found to contain traces of cystine. A portion of this glutamic acid was, therefore, treated with hydrogen peroxide to oxidize the cystine (Rode, Lankford \& Schuhardt, 1951) and another portion was recrystallized six times from water. In media made with these treated samples of glutamic acid no growth of Haemophilus pertussis appeared during 8 days of incubation, unless cystine or cysteine were added. In view of these results $50 \mathrm{~g}$. of the L-glutamic acid specimen were purified by recrystallization and used for the preparation of the basal medium.

Solutions of the various sulphur compounds were made to contain equal concentrations of sulphur and the solutions of sodium sulphate, sulphite, thiosulphate and taurine were autoclaved to sterilize. The solutions of sodium hydrosulphite, sodium sulphide, cystine, cysteine, homocystine, methionine, glutathione, mercaptoacetic acid and cysteic acid were sterilized by filtration through a sintered-glass filter. After sterilization, dilutions were prepared to contain concentrations equivalent to 25.0 and $5.0 \mu \mathrm{g}$. S $/ \mathrm{ml}$. and $1.0 \mathrm{ml}$. volumes of these were added to tubes containing $4.0 \mathrm{ml}$. of basal medium. A series of tubes was seeded with the standard inoculum of each of four strains (including strain 724) and incubated for 7 days. No growth was observed with 
any sulphur compound except cystine, cysteine and glutathione; the growth with the latter compound was only one-eighth of that obtained with cystine at an equivalent concentration of sulphur.

As it was considered possible that other compounds might be utilized when autocalved in the medium, sodium sulphate, sulphite and thiosulphate, methionine, mercaptoacetate, homocystine and taurine were added to the basal medium before it was autoclaved. After autoclaving, the tubes were seeded with the standard inoculum of strain 724 and incubated for 7 days. No growth occurred.

To determine whether other compounds could be used in the presence of minimal concentrations of cystine, this compound was added to the basal medium in sufficient quantity $(1.9 \mu \mathrm{g} . / \mathrm{ml}$., equivalent to $0.5 \mu \mathrm{g}$. S $/ \mathrm{ml}$.) to give one-sixth to one-eighth maximal growth and then sulphite, thiosulphate, methionine, mercaptoacetate or taurine $(5 \cdot 0 \mu \mathrm{g} . \mathrm{S} / \mathrm{ml}$.) was added. These compounds did not increase the growth of strain 724 above that which occurred in the medium containing a minimal concentration of cystine.

It appears, therefore, that of the compounds tested only cystine, cysteine and glutathione served as a source of sulphur for the strains of Haemophilus pertussis tested. The amount of growth of strain 724 with various concentrations of cystine or cysteine (added before and after autoclaving the medium) is shown in Fig. 1. The higher concentrations of cysteine, when added after the medium had been autoclaved, inhibited growth. When cysteine was autoclaved in the medium no inhibition occurred and a nitroprusside test showed that the cysteine had been converted to cystine. In this medium $38 \mu \mathrm{g}$. cystine/ $\mathrm{ml}$. (equivalent to $10 \mu \mathrm{g}$. $\mathrm{S} / \mathrm{ml}$.) were necessary for maximum growth. From these results it appears that our previous observation of slight growth in a medium to which cystine had not been added (Jebb \& Tomlinson, 1955) could be accounted for by cystine present as impurity in the glutamic acid used. Our conclusion that methionine or sulphate might be used as a source of sulphur was not justified.

\section{Amino acid requirements}

The standard inoculum of Haemophilus pertussis strain 724 consistently grew in medium GF (about $200 \mu \mathrm{g}$. dry wt./ml. in 6 days). In order to be sure that glutamic acid and cystine were the only amino acids required it was necessary to establish that the observed growth was not due to the emergence of a less exacting variant and that growth could be maintained in serial subculture. Strain 724 was grown for 6 days in medium GF and the optical density of the culture measured; after dilution to give the standard size of inoculum a further lot of medium GF was inoculated; after 6 days of growth a second subculture was made. As all three cultures grew at the same rate it seems improbable that a variant was being selected.

In order to test more stringently the supposition that growth in medium GF was not due to a proportion of the organisms being less exacting than the majority, the smallest inoculum which would give growth was determined. Eight strains were grown on Bordet-Gengou medium and washed suspensions prepared; colony counts of these were performed, and dilutions made to 
provide a series of graded inocula. Each of three tubes of medium GF received $0.1 \mathrm{ml}$. of each dilution of inoculum and the tubes were incubated for 9 days. It would have been preferable to have used freshly isolated strains, but as these were not available the experiment was performed with cultures from freshly opened tubes of dried strains.

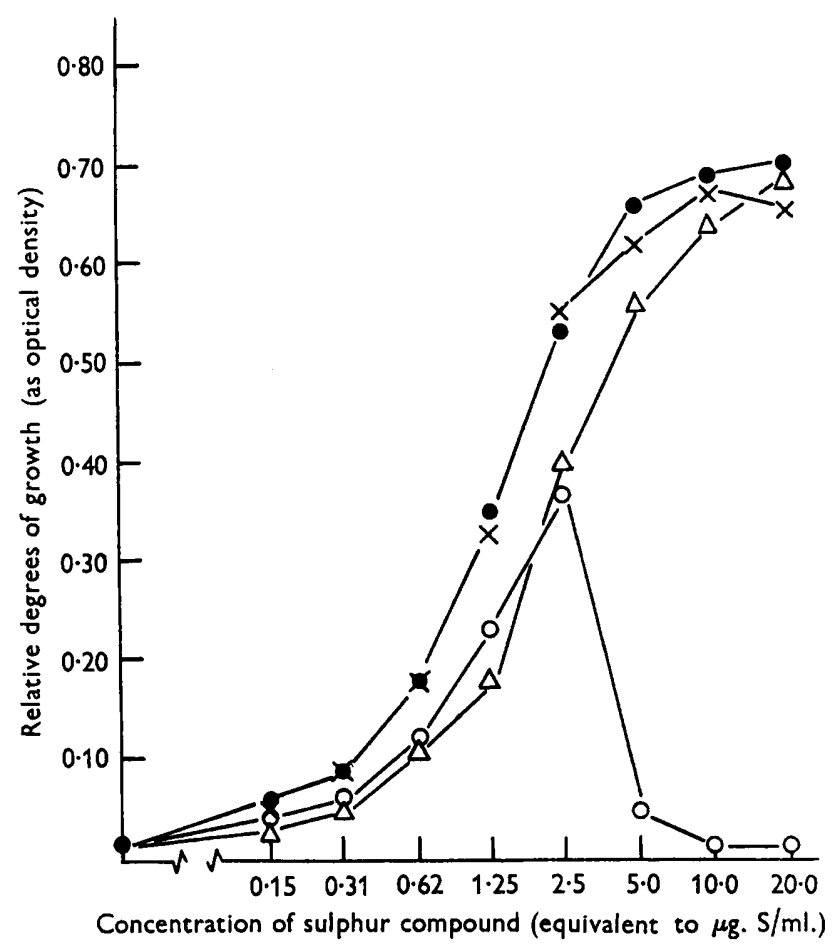

Fig. 1. Growth at 7 days, of Haemophilus pertussis strain 724, with various concentrations of cystine added before $(x)$ and, after $(\Theta)$, autoclaving; cysteine added before $(\triangle)$, and after $(O)$ autoclaving.

In every instance the inoculum from the $1 / 10^{8}$ dilution of the washed suspension grew and the colony counts showed that these inocula contained not more than 10 organisms which were viable on Bordet-Gengou medium. The high dilution eliminated the carry-over of significant amounts of amino acids with the inoculum and the occurrence of growth from an inoculum containing 3-10 viable organisms showed that either all the organisms were able to grow in the medium, or if a variant only were growing, that this variant must comprise $10-30 \%$ of the whole population.

To confirm that growth could be maintained in serial subculture, the standard inocula of Haemophilus pertussis strains 724, 2439 and 10434 were put into medium GF, and after 6 days of growth a small loopful was transferred to fresh medium. Growth was maintained through 9 serial subcultures with no sign of diminution and it was concluded that the amino acid requirements of the strains of $H$. pertussis used were satisfied by glutamic acid + cystine. 
Whereas nicotinic acid was the only vitamin added by Proom (1955) to his media, medium GF also contained guanine, hypoxanthine, xanthine, biotin and haemin, since these compounds had been found by Jebb \& Tomlinson (1955) to stimulate growth. To determine whether the minimal amino acid requirements were more elaborate when nicotinic acid was the only growth factor present, medium $\mathbf{G}$ was supplemented with: (i) nicotinic acid; (ii) nicotinic acid+purines; (iii) nicotinic acid + purines + biotin + haemin; (iv) nicotinic acid + biotin + haemin. Strains 724, 8126, 2439 and 10434 were carried through four serial subcultures in these media. Although growth was slower in medium (i) than in medium (iii) there was no suggestion that it became poorer with successive passages, and there was thus no indication that the amino acid requirements were more complex in the absence of purines, biotin and haemin.

These findings with regard to amino acid requirements are at variance with those of Proom (1955), and the discrepancy may be due to the difference in time of incubation. Proom did not state how long he incubated his cultures but said that his methods were similar to those used by Knight \& Proom (1950) who stated that 'growth was determined by visual observation... up to 3-4 days'; this might well be too short a period in which to observe the growth of Haemophilus pertussis in simple media, after the first few subcultures.

In work on the nutrition of a variable organism like Haemophilus pertussis, which is prone to degenerate in laboratory culture, it is preferable to use small washed inocula rather than to attempt serial passage of large inocula. When tested, however, by either method the strains of $\boldsymbol{H}$. pertussis used grew in a medium containing only two added amino acids.

\section{REFERENCES}

Hornibrook, J. (1939). Cultivation of phase I H. pertussis in semi-synthetic liquid media. Publ. Hlth Rep., Wash. 54, 1847.

ImAMURA, P. S. (1952). Growth requirements of $\boldsymbol{H}$. pertussis with special reference to the production of thermolabile toxin. Japan J. exp. Med. 22, 49.

JEBB, W. H. H. \& Tomuinson, A. H. (1951). The catabolic activity of washed suspensions of Haemophilus pertussis. J. gen. Microbiol. 5, 951.

JebB, W. H. H. \& Tomminson, A. H. (1955). The nutritional requirements of Haemophilus pertussis. J. gen. Microbiol. 13, 1.

Knight, B. C. J. G. \& Proom, H. (1950). A comparative survey of the nutrition and physiology of mesophilic species in the genus Bacillus. J. gen. Microbiol. 4, 508.

Proom, H. (1955). The minimal nutritional requirements of organisms of the genus Bordetella López. J. gen. Microbiol. 12, 63.

Rode, L. J., Lankford, C. E. \& Schuhardt, V. T. (1951). Studies of sulfur metabolism of Brucella suis. J. Bact. 62, 571.

Ungar, J., James, A. M., Muggleton, P. W., Pegler, H. F. \& Tomich, E. G. (1950). The cultivation of Haemophilus pertussis in partially defined liquid media. J. gen. Microbiol. 4, 345.

Verwey, W. F., Thiele, E. H., Sage, D. N. \& Schuchardt, L. F. (1949). A simplified liquid culture medium for the growth of Hemophilus pertussis. J. Bact. 58,127 .

(Received 7 January 1957) 